EDUR • Educação em Revista. 2020; 36:e222301

DOI: http://dx.doi.org/10.1590/0102-4698222301

(9) (1) https://creativecommons.org/licenses/by/4.0/

\title{
OS TRABALHADORES NOS LIVROS DIDÁTICOS DE HISTÓRIA NA SEGUNDA REPÚBLICA ${ }^{1}$ (1930-1945)
}

\author{
JOÃO HENRIQUE ZANELATTO ${ }^{2}$ \\ https://orcid.org/0000-0002-1754-1001 \\ RAYANE LAYRA DE SOUZA ${ }^{3}$ \\ https://orcid.org/0000-0002-3649-3009?lang=en
}

Resumo: $\mathrm{O}$ escrito objetivou analisar como as relações de trabalho são apresentadas nos livros didáticos de História (atuais), utilizados pelos professores de História nas escolas públicas estaduais e municipais brasileiras. Nos últimos 20 anos, vem ocorrendo a distribuição de livros por meio de uma política de Estado, que ocasionou o surgimento de um mercado editorial extremamente rentável, disputado por várias editoras. A cada três anos, os livros são substituídos por novos, e são os professores, de modo geral, que escolhem aqueles a serem utilizados no triênio seguinte. O estudo fundamentou-se na História Social do Trabalho, elegendo como fontes de pesquisa a produção bibliográfica sobre o período e a análise de cinco livros didáticos utilizados pelos professores de História das escolas públicas municipais e estaduais em todo o território nacional, no triênio 2017-2019, buscando analisar como os trabalhadores foram abordados nesses livros.

Palavras-chave: Trabalhadores, Livros didáticos, Segunda República.

\section{THE WORKERS IN THE DIDACTIC BOOK OF HISTORY IN THE SECOND REPUBLIC (1930-1945)}

\begin{abstract}
This paper aims to analyze how labor relations are presented in History textbooks (current), used by History teachers in Brazilian state and municipal public schools. In the last 20 years, there has been a distribution of books through a State policy, which has led to the emergence of an extremely profitable publishing market disputed by several publishers. Every three years the books are replaced with new ones and usually, teachers choose the books to be used in the next three years. The study was based on the Social History of Work,
\end{abstract}

\footnotetext{
${ }^{1}$ Neste escrito, utilizamos a noção de Segunda República para o período de 1930 a 1945, divergindo de uma historiografia que, de modo geral, apresenta o período como "Era Vargas", presente também nos livros didáticos analisados.

2 Doutor em História e docente permanente do Programa de Pós-Graduação em Desenvolvimento Socioeconômico e do Curso de História na Universidade do Extremo Sul Catarinense (UNESC). Criciúma, SC, Brasil.<jhz@unesc.net>

${ }^{3}$ Graduada em História e Mestranda no Programa de Pós-Graduação em Desenvolvimento Socioeconômico pela Universidade do Extremo Sul Catarinense. Bolsista FAPESC. Criciúma, SC, Brasil. $<$ rayanelayra@gmail.com>
} 
choosing as sources of research the bibliographic production on the period and the analysis of five textbooks used by the History teachers of the municipal and state public schools throughout the national territory in the period 2017-2019, seeking to analyze how workers were approached in these books.

Keywords: Workers, Didatic books, Second Republic.

\section{TRABAJADORES EN LIBROS DIDÁCTICOS DE HISTÓRIA EN LA SEGUNDA REPÚBLICA (1930-1945)}

Resumen: El objetivo del trabajo fue analizar cómo se presentan las relaciones laborales en los libros de texto de Historia (actuales) utilizados por los maestros de Historia en las escuelas públicas estatales y municipales de Brasil. En los últimos 20 años, ha habido una distribución de libros a través de una política estatal, lo que ha llevado al surgimiento de un mercado editorial extremadamente rentable disputado por varias empresas editoriales. Em cada tres años, los libros se reemplazan por libros nuevos y son los maestros quienes generalmente eligen los libros que se utilizarán durante los próximos tres años. El estudio se basó en la Historia social del trabajo, eligiendo como fuentes de investigación la producción bibliográfica sobre el período y el análisis de cinco libros de texto utilizados por los profesores de Historia de las escuelas públicas municipales y estatales en todo el territorio nacional en el período 2017-2019, tratando de analizar cómo se abordó a los trabajadores en estos libros.

Palabras clave: Trabajadores, Libros didácticos, Segunda República.

\section{INTRODUÇÃO}

O grande investimento em políticas de produção e distribuição de Livros Didáticos nos últimos 20 anos oportunizou o surgimento de um vasto e lucrativo mercado editorial. Esses materiais didáticos passaram a ser entregues aos alunos da rede pública a cada três anos, gerando ampla demanda de produção para as editoras. Esse processo tem alterado a imagem desses livros, os quais passaram a ser vistos muito mais como um elemento comercial do que como apoio material nas salas de aula.

Considerando a nova estrutura na qual o processo de escolha e produção do livro didático está inserido e compreendendo a grande variedade de estudos desenvolvidos na historiografia sobre a Segunda República, tem-se como objetivo analisar como são apresentadas as relações de trabalho em cinco livros didáticos utilizados pelos professores de História das escolas públicas municipais e estaduais brasileiras durante o triênio 2017-2019. Com esta pesquisa, busca-se responder ao seguinte questionamento: Como os trabalhadores são apresentados nos capítulos referentes à Segunda República nos livros didáticos utilizados no triênio 2017-2019?

O presente estudo fundamentou-se na História Social do Trabalho, em especial nas discussões produzidas por E. P. Thompson, como, por exemplo, sobre os conceitos de classe, luta de classe e experiência, abordados pelo autor. Thompson discorda da ideia de classe como "coisa"; ele a define como uma construção social. O autor criou o conceito de "Experiência" para melhor analisar a classe trabalhadora, fazendo um contraponto à visão de Althusser, que, assim como outros teóricos, traz o modo de produção se sobressaindo à formação social. 
Para possibilitar as reflexões sobre a Segunda República, a presente pesquisa se embasou nos estudos de Ângela de Castro Gomes, em especial na obra "Invenção do trabalhismo" (2005), na qual a autora aborda as relações sociopolíticas da classe trabalhadora e a construção da imagem e do poder do Governo Vargas.

Para compreender as dificuldades que permeiam a pesquisa sobre os livros didáticos e buscando bases para analisar esses materiais de uma forma mais adequada e direcionada para o estudo desse tipo de fonte, foram utilizadas as reflexões de Circe Bittencourt na obra "Ensino de História: Fundamentos e métodos" (2004), na qual a autora trata dos processos de ensino-aprendizagem em História, levantando problemáticas acerca dos materiais didáticos, bem como dos processos que permeiam a sua escolha e utilização.

Para desenvolver esta pesquisa, foram analisados cinco livros didáticos, considerando-se três pontos principais: a) os aspectos formais, b) os conteúdos históricos escolares e c) os conteúdos pedagógicos.

\section{O ESTADO DIRIGIDO POR VARGAS E O CAPITAL BUSCANDO CONTROLAR OS TRABALHADORES}

Ao pensar no contexto sociopolítico do Brasil no período em que Vargas ascendeu ao poder, depara-se com um momento em que a situação do País, tanto no plano econômico quanto no plano político, estava sendo repensada. Esse período foi marcado por um processo de centralização do poder no Governo Federal e de quebra das oligarquias tradicionais regionais.

O crescimento de movimentos sociais e políticos na década de 1920 fez com que o Fantasma da Revolução Russa assombrasse setores das elites intelectuais e políticas brasileiras. A questão social passou a ser debatida intensamente e muitos questionaram as instituições liberais vigentes pela incapacidade de vencer o "atraso" e a "desordem" reinante no país. (CAPELATO, 2003, p. 110)

A conjuntura econômica brasileira se encontrava, desde meados de 1920, em movimento de desaceleração; o que só se agravou com a crise de 1929, já que com uma política econômica voltada essencialmente para a produção agrícola de exportação de basicamente um produto, a economia foi profundamente afetada, e tanto a indústria, o comércio e o setor agrícola se encontravam em grandes dificuldades, ocasionando diversas falências e inúmeros casos de desemprego (GOMES, 2015).

Segundo Pandolfi (2003), o contexto socioeconômico e o descontentamento com os resultados das eleições de 1930 fizeram com que um movimento surgisse e fosse posto em prática principalmente por alguns grupos de civis e por parte dos tenentes. Esse movimento culminou na chamada Revolução de 1930, a qual possibilitou que, no dia 3 de novembro, Getúlio Vargas assumisse o comando do Governo Provisório da Nação, efetuando de imediato diversas medidas centralizadoras e intervencionistas, como o fechamento do Congresso Nacional e das assembleias estaduais e municipais, mandando

\footnotetext{
${ }^{4}$ Os livros escolhidos para serem utilizados como fontes para esta pesquisa são os seguintes: História: Projeto Mosaico, do $9^{\circ}$ ano do ensino fundamental, escrito pelos historiadores Cláudio Vicentino e José Bruno Vicentino, publicado pela editora Scipione; História, Sociedade e Cidadania, do $9^{\circ}$ ano do ensino fundamental II, escrito por Alfredo Boulos Júnior, publicado pela editora FTD; Coleção Integralis, do $9^{\circ}$ ano do ensino fundamental, escrito por Pedro Santiago, Maria Aparecida Pontes e Célia Cerqueira, produzido pela editora IBEP; Projeto Araribá, do $9^{\circ}$ ano do ensino fundamental II, que tem como editora responsável Maria Raquel Apolinário, escrito e publicado de forma coletiva em parceria com a Editora Moderna; História Doc, do $9^{\circ}$ ano do ensino fundamental II, escrito por Ronaldo Vainfas, Sheila de Castro Faria, Jorge Ferreira e Daniela Buono Calainho, publicado pela editora Saraiva.
} 
depor os governadores de estado e nomeando interventores. Além disso, passou a gerenciar o País e o seu governo apenas por meio de decreto-lei.

A política voltada para a promoção da imagem positivada de Vargas contribuiu, por muitas vezes, para o apagamento do processo em torno das questões sociais, que vinham ocorrendo antes mesmo do governo Vargas. Segundo Gomes (2015), desde as primeiras décadas do século XX, o movimento operário por meio das associações e cooperativas já promovia debates sobre o trabalho e sobre as questões sociais. Eram questionados os deveres tanto do Estado quanto das indústrias ante a regulamentação do trabalho.

"A Lei de sindicalização de 1931 vinha transformar e, ao mesmo tempo, concorrer com o padrão de associações até então existentes no movimento operário" (GOMES, 2005, p. 163). Com essa nova legislação, o Estado passou a exercer um controle sobre os sindicatos, estabelecendo a carta sindical que deveria ser emitida com a autorização do Ministério do Trabalho para que o sindicato fosse criado. Estabeleceu também as contribuições obrigatórias, a unicidade sindical, entre outras medidas autoritárias (D'ARAÚJO, 2003).

Segundo Gomes (2015), os dirigentes que estavam no comando do Estado acreditavam que, a partir da reformulação, deveriam ser rompidas todas as ligações com o modelo anterior, tratando de outra forma o papel do Estado na sociedade e a relação com o trabalho. Assim, a maior intervenção do Estado não seria mais vista no sentido da proteção física do trabalhador e sim como uma nova forma de gerir as relações sociais que permeiam os interesses de patrões e dos trabalhadores. Dessa forma, as articulações sobre as resoluções das questões sociais no Brasil, durante a década de trinta, possibilitaram, ao mesmo tempo, o afastamento pelo menos temporário da ameaça socialista ao desarticularem os movimentos sociais e serviram como uma ótima base política para a promoção do governo Vargas.

De acordo com Boito Júnior (1991), a estrutura sindical, no Brasil, foi articulada muito mais para imobilizar a classe trabalhadora do que para torná-la combativa, pois dentro dessa estrutura o sindicato oficial é parte integrante do aparelho de Estado, estando subordinado à burocracia estatal. À vista disso, o processo de sindicalização coloca os trabalhadores sobre a tutela do Estado, fazendo com que o sindicato tenha a função de intermediar a relação dele com o trabalhador, promovendo, muitas vezes, o apaziguamento das lutas de classe.

Desde o início do século XX, havia no Brasil uma corrente sindical conhecida como amarelos, que pontuava sua atuação pela cooperação com os poderes constituídos. Com Vargas não se inicia, portanto, essa modalidade de sindicalismo. O que houve foi uma adaptação dessa tradição para uma necessidade do modelo político e econômico instalado no período. O peleguismo foi transformado na corrente sindical legítima, reconhecida pelo Estado, única maneira possível de se desenvolverem atividades sindicais (D'ARAÚJO, 2003).

$\mathrm{O}$ sindicato pelego atuou na função de conciliador entre os trabalhadores, os patrões e o Estado, fazendo um papel duplo, representando os trabalhadores, mas não entrando em conflito direto com os interesses do Estado e do Capital, "amortecendo" as relações entre eles (D'ARAÚJO, 2003).

Com vertentes mais ligadas à esquerda, os sindicatos foram aqueles que mais se mantiveram relutantes à reestruturação e ao novo modelo corporativista. Por mais que desejassem o reconhecimento do poder sindical e sua legalidade, compreendiam que os moldes impostos pelo Estado tinham a função de colocar sob sua tutela as organizações dos trabalhadores (BARISTELA, 2015).

Em síntese, até 1930, o Estado brasileiro atuou de forma Liberal na relação com os trabalhadores. Não havia regulamentação, então estava livre para reprimi-los. No pós-30, a relação com os trabalhadores mudou substancialmente. $\mathrm{Na}$ medida em que o sindicato passa a ser uma figura jurídica de colaboração com o Estado, a repressão não se faz mais via polícia. O que passa a ser feito é um intenso controle, devidamente regulado em uma série 
de leis. Redefinem-se as funções desse órgão, adequando-o ao novo formato do Estado corporativo emergente e ao processo de mudança econômica que o País atravessava (D'ARAÚJO, 2003).

Segundo Thompson (1987), os trabalhadores, de modo geral (homens e mulheres), estão sempre inseridos nas condições institucionais e ideológicas impostas a eles, entretanto, além disso, são sujeitos do seu próprio meio, não sujeitos totalmente livres, autônomos, mas que lidam com suas próprias experiências dentro das relações de produção, interligadas com a cultura e o seu meio social, exercendo suas ações por intermédio de sua experiência, criada de forma interligada nesse contexto.

As pessoas não experimentam sua própria experiência apenas como ideia, no âmbito do pensamento e de seus procedimentos ou (como supõem alguns praticantes teóricos) como instinto proletário, etc. Elas também a experimentam como sentimentos, lidando com eles na cultura; como normas, obrigações familiares e de parentesco; como reciprocidade e valores ou (por meio de formas mais elaboradas) na arte e nas convicções religiosas. Essa metade da cultura (e é uma metade completa) pode ser descrita como uma consciência afetiva e moral (THOMPSON, 1987).

Para determinar a produção historiográfica, a formação da classe operária, no Brasil, estava associada ao processo de crescimento industrial, que ocorreu a partir 1880, promovendo a concepção de que a classe é um efeito automático da estrutura produtiva, sem considerar que a existência de trabalhadores fabris não garante a sua existência. Sendo a formação de classe um processo conflituoso, marcado por avanços e recuos, pelo fazer-se da classe junto da organização, de ações, de concepções e de instituições coletivas (BATALHA, 2003).

Segundo Gomes (2005), o processo de construção da classe trabalhadora no Brasil ocorreu em dois movimentos dentro de seus respectivos períodos. O primeiro teria ocorrido de forma gradual, durante a Primeira República, quando o trabalhador era o principal autor de suas lutas, e as principais lideranças eram intensamente ligadas ao operariado. Já o segundo momento teria ocorrido durante o Governo Vargas, com a proposição de uma identidade imposta sobre a classe trabalhadora pelo Estado, na tentativa de conter e controlar o movimento.

É possível observar, na Primeira República, um movimento intenso das organizações trabalhistas. Durante o período de 1917 a 1919, por exemplo, foram criadas inúmeras organizações operárias nas cidades do Rio de Janeiro e de São Paulo. Esse volume de associações tendia a ser particularmente visível em momentos nos quais os trabalhadores tinham maior poder de barganha e assim maior sucesso em suas reivindicações. Como as greves de 1902-1903, 1906-1907, 1917-1919 ou o movimento contra a carestia de vida de 1913, momentos significativos da ação coletiva que envolviam a sociedade e não apenas os trabalhadores pertencentes às sociedades operárias. Em momentos como esses, nos quais os interesses coletivos ultrapassam os interesses individuais e corporativos, é que a classe, como uma realidade histórica, pode ser considerada efetiva (BATALHA, 2003).

Já o período da Segunda República traz consigo um estereótipo nas questões trabalhistas, pois as relações entre os trabalhadores e o Estado, nesse período, foram, muitas vezes, positivadas devido à grande reestruturação efetuada. Nessa visão, os trabalhadores são tratados como estando de acordo com as ações do Estado ou como subjugados e desarticulados ante as medidas.

Destarte, ao pensarmos na experiência desses trabalhadores no contexto autoritário do Governo Vargas, temos que nos voltar para as suas articulações, lutas e resistências ante esse período, pois, mesmo com o desenvolvimento de diversas medidas controladoras emitidas por Vargas, o movimento não se findou totalmente.

Devido à criminalização do direito de greve em 1935 e em 1937, nota-se uma alteração no conceito de greve, o qual fez com que os trabalhadores que não tinham ligação 
com os movimentos de esquerda passassem a ver o movimento grevista como algo errado. "Ou seja, os trabalhadores não faziam greves, mas apenas paravam de trabalhar por melhores condições” (SIQUEIRA, 2015, p. 234).

Usualmente, duas hipóteses fomentam a ausência de greve no Estado Novo. Aquela que afirma a cooptação do trabalhador pelo sistema "trabalhista" do Governo Vargas, com a criação dos sindicatos únicos, do imposto sindical e de outras medidas, dentre elas uma série de direitos sociais que foram positivados durante todo esse governo (1930-1945), e uma outra que vê na grande violência do aparato estatal, da polícia política, e no uso do exército contra o povo a principal causa do silêncio dos trabalhadores. Por óbvio, ambas as hipóteses não são excludentes e poderiam muito bem conviver de forma conjunta (SIQUEIRA, 2015).

Dessa forma, nota-se que, ao contrário do que de maneira geral é reproduzido na historiografia, durante o período do Estado Novo, ocorreram diversas greves. Mesmo que tomando diferentes conotações, é possível encontrar diversos processos no Tribunal de Segurança Nacional (TSN) que demonstram a presença de greves no período. Exemplos do exposto foram as greves que envolveram os operários da Fábrica Votorantim, em Sorocaba, SP, em maio de 1941, e as que tiveram a participação dos trabalhadores da Companhia de Mineração e Metalurgia Brasil (CoBrasil), em Laguna, SC (SIQUEIRA, 2015).

Portanto, por mais que esse período represente um avanço nos direitos trabalhistas, devem ser percebidas as relações que não estão enfatizadas nas produções sobre o período. Dessa maneira, mesmo que esse processo tenha promovido a implantação de ferramentas de controle sobre as organizações, a resistência e a luta dos trabalhadores não cessaram, demostrando que esses avanços não foram dádivas do Estado, mas sim conquistados nas lutas empreendidas pelos trabalhadores.

\section{A HISTÓRIA DOS TRABALHADORES ENSINADA PELOS LIVROS DIDÁTICOS}

De acordo com o Ministério da Educação - MEC (BRASIL, 2018), atualmente, o Programa Nacional do Livro Didático (PNLD) tem como principal função avaliar e disponibilizar obras didáticas, pedagógicas e literárias, bem como outros materiais que auxiliem na prática educativa, para escolas públicas de educação básica das redes federal, estadual, municipal e distrital e também às instituições de educação infantil comunitárias, confessionais ou filantrópicas sem fins lucrativos e conveniadas ao Poder Público.

Com o desenvolver desse programa, produzir e distribuir livros didáticos passou a significar uma chance de vendas para as editoras e não só de circulação de conhecimento. Construindo um mercado editorial muito disputado, já que a cada três anos os livros são substituídos por novos, promove-se, dessa forma, um processo de comercialização por meio da distribuição desses materiais. Assim, as escolhas dos livros didáticos por parte das escolas e dos professores foram, aos poucos, tomando outros rumos, colocando, muitas vezes, o processo de análise e pesquisa de escolha do melhor material didático no segundo plano (BENTO, 2008).

De acordo com Bento (2008), a falta de cuidado na escolha dos materiais vem abrindo espaço para a negligência por parte dos escritores e dos professores na construção dos conteúdos a serem trabalhados nas salas de aula, o que deixa margem para que o livro passe a ser visto como uma mera mercadoria, sendo produzidos materiais que passam a contrariar a lógica do pensamento histórico, pois, na maioria das vezes, eles fornecem aos alunos uma concepção de História única, não proporcionando a eles formas de exercer o raciocínio lógico e as múltiplas capacidades criativas. Isso contribui diretamente para a afirmação do estereótipo de que esse material é algo sacralizado, o qual não deve ser 
questionado. Isso ocorre porque os livros didáticos não são historicizados, ou seja, na maioria dos casos, tanto os autores quanto os professores não pensam tal material como sendo uma das várias interpretações possíveis.

O estudo da História é importantíssimo para o desenvolvimento intelectual do aluno, pois lhe possibilita formas de compreender os processos históricos que o cercam, contribuindo para a formação de um aluno com capacidade para fazer questionamentos e ponderações sobre os assuntos discutidos. Assim, essa defasagem prejudica diretamente a relação de ensino e aprendizagem dentro das salas de aula.

Seguindo essa premissa, foram selecionados cinco livros didáticos de História, sendo que alguns deles foram utilizados pelos professores nas escolas públicas estaduais e municipais brasileiras durante o triênio 2017-2019. Neles, buscou-se identificar como os trabalhadores foram apresentados nos capítulos referentes ao conteúdo da Segunda República.

Para o desenvolvimento desta pesquisa, foram analisadas três questões principais em relação aos livros didáticos: a) os aspectos formais, b) os conteúdos históricos e c) os conteúdos pedagógicos. No que concerne aos aspectos formais, procurou-se identificar a estrutura do livro, o número de capítulos e de páginas, as informações gerais, como nomes dos autores e da editora, e os demais sujeitos que interferiram na obra (editores, gráficas, ilustradores ou pesquisadores de materiais gráficos e revisores de texto). Especificamente sobre o capítulo, foi observado o seguinte: se há uma introdução ou apresentação, um índice, glossários, bibliografia e como ele foi dividido.

Depois, examinando os conteúdos históricos escolares, buscou-se identificar qual é a tendência histórica predominante no livro (marxista, histórico-cultural, metódica, tendência ao ecletismo, etc.) e como são apresentados os conteúdos históricos, a fim de identificar se são textos que dificilmente levam à contestação e que impedem a reflexão, se eles se apresentam como "uma verdade" ou se possibilitam a contestação, a reflexão e a problematização. Por fim, observou-se como são as explicações e quais são os conceitos introduzidos ou retirados.

Quanto aos conteúdos pedagógicos, foi analisado se as atividades contidas nos capítulos contribuem para a apreensão dos conteúdos, se possibilitam ao aluno comparar e identificar semelhanças e diferenças entre os acontecimentos. Buscou-se perceber se existe relação entre a proposta do conteúdo do capítulo e os exercícios e se eles possibilitam a reflexão ou se são baseados em textos de múltipla escolha que levam somente à memorização.

\section{HISTÓRIA MOSAICO}

Este livro didático de História do $9^{\circ}$ ano do ensino fundamental II foi escrito pelos historiadores Cláudio Vicentino e José Bruno Vicentino e publicado pela editora Scipione. A obra conta com a participação da diretora do editorial, Lidiane Vivaldine Olo; do supervisor de arte, Ricardo de Gan Braga; e do supervisor de iconografia, Silvio Kliguin. Contém 470 páginas e possui 17 capítulos, os quais foram subdivididos em oito módulos, nos quais os autores seguem relacionando a História do Brasil com a História Geral. Em suas primeiras páginas, o livro oferece aos leitores um manual explicativo para facilitar a sua utilização.

O capítulo intitulado "A Era Vargas" contém 16 páginas e está inserido no módulo quatro, denominado "A Era Vargas e o mundo em Guerra", dividido de forma cronológica e por temas específicos. A narrativa é iniciada com uma pequena introdução sobre o período, apresentando duas fotos (a primeira de um grupo Integralista, e a outra de mulheres votando pela primeira vez), mas sem discutir a seu respeito e/ou problematizá-las, 
trazendo apenas um questionamento sobre as ameaças e os direitos que surgiram nesse período, colocando-as como meras ilustrações visuais e deixando a cargo do professor provocar a discussão.

No capítulo analisado, nota-se que a linha histórica segue uma tendência ao ecletismo, com maior ênfase para as questões econômicas e políticas. Os autores apresentam os conteúdos de forma cronológica, seguindo uma linha do tempo, muito comum na História "tradicional" ". Em alguns momentos, os conteúdos acabam sendo apresentados como verdades únicas, pois não são discutidas as diferentes visões historiográficas. Os autores fazem uso do conceito de "revolução de 30" para denominar o movimento que deu poder a Getúlio Vargas, mas sem problematizar as outras visões historiográficas.

Uma singularidade do capítulo foi abordar os conflitos do campo, conteúdo que não aparece nos outros livros didáticos, como é possível ser observado na imagem apresentada abaixo.

Figura 1 - Conflitos no campo



Fonte: Vicentino e Vicentino (2015, p. 143).

No texto da figura, os autores demonstram como as políticas sociais desenvolvidas durante a Segunda República foram direcionadas quase que totalmente para as áreas urbanas, deixando a maioria da população que vivia no campo sem assistência. "A legislação sindical, ao criar alguns direitos apenas para os trabalhadores urbanos, introduziu uma maneira de tornar o trabalho industrial mais atrativo" (D'ARAÚJO, 2003, p. 220).

Ao tratarem da relação dos trabalhadores com o Governo Vargas, os autores citam a criação de diversas leis que atenderam a parte dos anseios dos trabalhadores industriais. No entanto, de forma superficial, eles mostram como algumas dessas medidas foram estratégicas, as quais o Estado articulou para manter os sindicatos sob seu domínio e afastá-los do poder. Discutem o papel da imprensa e do rádio na construção das políticas nacionalistas do Governo Vargas perante os trabalhadores; denunciam o processo de censura

5 A História tradicional a que nos referimos neste escrito nos remete à Escola Metódica. Sobre a Escola Metódica ver: REIS, José Carlos. A história, entre a filosofia e a ciência. 4. ed. Belo Horizonte: Autêntica Editora, 2011. 
dos meios de comunicação; mostram como essas ações autoritárias foram pensadas com o intuito de promover a política paternalista de Vargas, consolidando a sua imagem à do "pai dos pobres", porém não apresentam as ações dos trabalhadores perante essas medidas nem buscam ressaltar suas experiências no processo de resistência. Dessa forma, acabam por apresentar os trabalhadores como subjugados pelo Governo Vargas.

No que se refere à linguagem utilizada nas explicações, é possível perceber a tentativa dos autores de discorrer de forma simples e acessível para os alunos. No entanto, como eles não utilizam glossário, algumas palavras utilizadas poderão não ser compreendidas corretamente, necessitando do auxílio do professor. E são trazidas algumas sugestões, no decorrer do capítulo, de obras complementares para leitura e de filmes, possibilitando que o aluno possa, através de seus estudos, comparar e diferenciar as perspectivas.

Em relação às atividades propostas pelos autores, de maneira geral, elas não estimulam o questionamento. A maioria acaba induzindo a resposta do aluno, pois não propõe a problematização dos conteúdos apresentados. Ao questionar a situação do operariado e sua relação com o Governo Vargas, as atividades acabam por estimular a visão do trabalhador como acomodado ou como subjugado, fazendo um comparativo com o movimento operário de 1920 e reforçando a ideia de que o movimento trabalhista foi extinto nesse período, sem problematizar as ações dos trabalhadores perante as medidas autoritárias.

\section{HISTÓRIA, SOCIEDADE E CIDADANIA}

Esse livro didático de História do $9^{\circ}$ ano do ensino fundamental II foi escrito pelo historiador Alfredo Boulos Júnior e produzido pela editora FTD. Conta com 16 capítulos, os quais foram subdivididos em quatro unidades. Nele, o autor segue relacionando cronologicamente a História do Brasil com a História Geral. Boulos enfatiza a importância dos vários profissionais que contribuíram para a formação do livro, como a editora Natália Taccetti e seus assistentes; a coordenadora de arte Daniela Máximo e os demais profissionais de iconografia; e também a coordenadora de preparação e revisão Lilian Semenichin, entre outros profissionais que trabalharam na produção do livro.

O capítulo denominado “A Era Vargas” tem 18 páginas, está inserido na unidade dois, intitulada "Política e propaganda de Massas". A narrativa é iniciada com uma breve contextualização da Segunda República, propondo a problematização das diferentes visões da imagem do governo de Getúlio Vargas.

Nas explicações, o autor busca mostrar esse período inserido em um processo político heterogêneo, permeado por tensões entre os divergentes grupos políticos da época. Ao tratar dos conceitos de Golpe e de Revolução, propõe a problematização do movimento que ocorreu em 1930, utilizando duas versões historiográficas. Ele possibilita aos alunos entender os dois conceitos e as diferentes interpretações sobre esse período, estimulando o questionamento e mostrando a História como feita de versões e não como uma única verdade. A tendência histórica predominante no livro é a de ecletismo, trabalhando principalmente as questões políticas e econômicas.

Ao abordar sobre os trabalhadores da época e o contexto sociopolítico no qual estavam inseridos, Boulos Júnior trabalha principalmente com a linha histórica que traz a relação entre o Governo Vargas e os trabalhadores como uma forma de construção da política populista. Como é possível observar na imagem apresentada abaixo, o autor procura problematizar os discursos nacionalistas de Vargas, utilizando um boxe com um texto da historiadora Maria Helena Rolim Capelato. 
Figura 2 - As abelhas e a colmeia

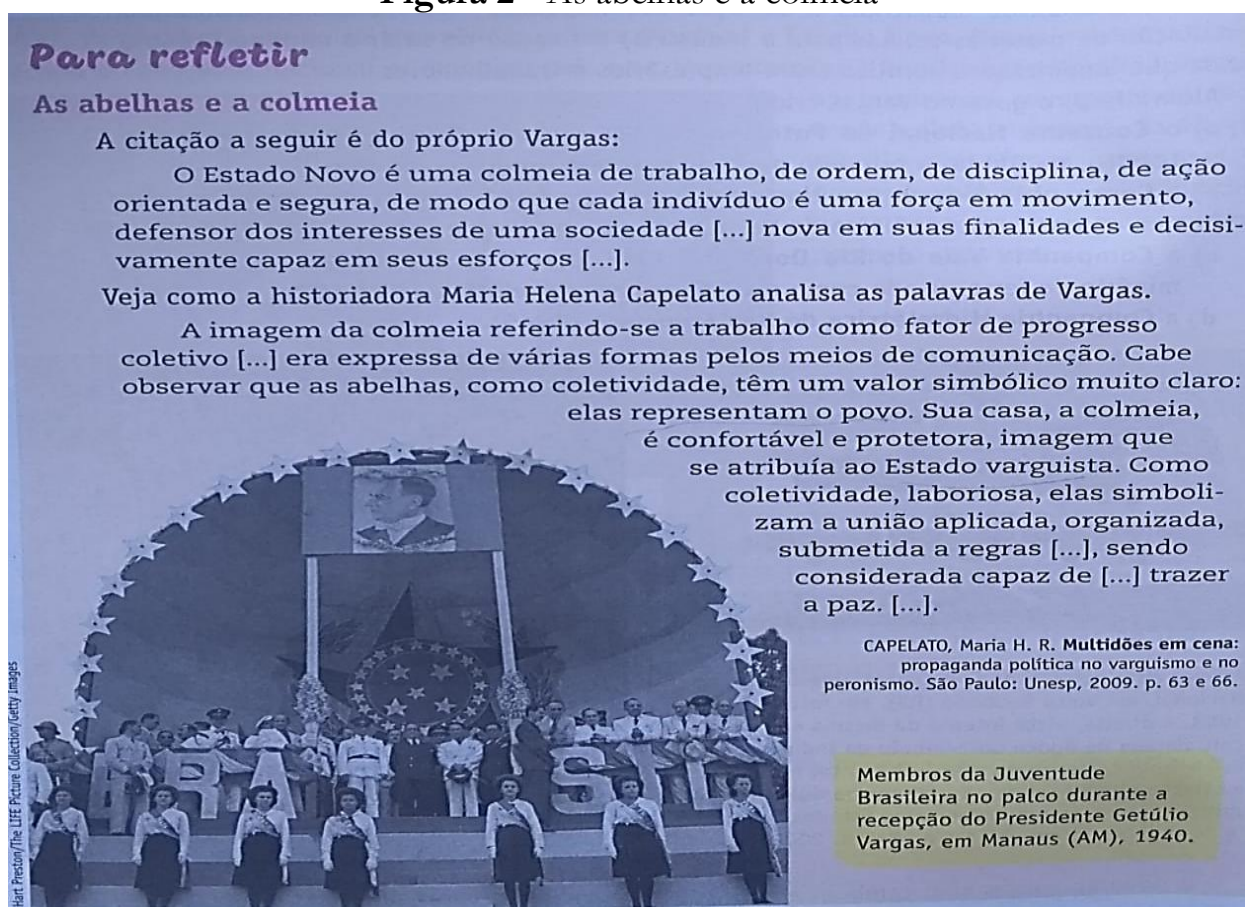

Fonte: Boulos Júnior (2015, p. 148).

Nessa discussão, a historiadora procurou questionar o ideal nacionalizador produzido por Vargas em um de seus discursos, no qual ele compara o povo às abelhas e o Estado Novo à colmeia, propondo que as abelhas (trabalhadores, principalmente) devem produzir muito e agir de forma ordeira, obedecendo ao líder da colmeia (Getúlio Vargas) para que assim construam uma nação mais forte.

Ao tratar da relação do Estado com os trabalhadores, é possível observar que o autor procura enfatizar o período do Estado Novo como autoritário, mas sem problematizar as medidas de controle impostas à classe trabalhadora desde o início do Governo Provisório. Aborda efetivamente a política do "trabalhismo", discutindo como o Estado articulou formas de estabelecer um vínculo entre o presidente e os trabalhadores, citando o processo de censura instaurado por Vargas. Ao definir os avanços nas questões trabalhistas como uma concessão feita pelo governo aos trabalhadores para mantê-los sob sua tutela, não enfatiza o papel das organizações operárias na conquista desses direitos. Deixa a entender que os trabalhadores, nesse período, ficaram desarticulados e submetidos ao Estado.

$\mathrm{O}$ autor trabalha muitas imagens, que aparecem no contexto dos assuntos discutidos, oportunizando variadas perspectivas. Utiliza também charges, propondo aos alunos problematizar as intencionalidades postas sobre elas. Boulos Júnior utiliza uma linguagem acessível aos alunos, faz uso de glossário para trazer o significado de diversas palavras, oportunizando uma melhor compreensão do que está ali proposto.

As atividades que são elaboradas durante o decorrer do capítulo se mostram mais vinculadas ao texto, trazendo mais aprofundamento ao conteúdo, com foco em sua reflexão. Durante o discorrer do capítulo, o autor traz questões com o intuito de mostrar a História enquanto versão para estimular no aluno as habilidades de argumentar e comparar. Já as atividades que estão no final capítulo, relacionadas ao movimento operário e à relação com o governo Vargas, são propostas apenas questões que discutem o "paternalismo" e as ações desenvolvidas em prol dos direitos trabalhistas, que acabam por positivar a imagem do Governo Vargas. 


\section{COLEÇÃO INTEGRALIS}

Esse livro foi escrito pelo historiador Pedro Santiago, pela pedagoga Maria Aparecida Pontes e pela bibliotecária Célia Cerqueira. Foi produzido pela editora IBEP, tendo como diretora editorial Célia de Assis; coordenadora de arte Karina Monteiro; e coordenadora de iconografia Neuza Faccin. No início do livro, encontram-se duas páginas nas quais o autor propõe ao aluno um espaço para entender como está organizado o livro didático. Logo em seguida, aparece o sumário. Os autores seguem relacionando a História do Brasil com a História Geral. O livro contém 456 páginas, onde estão distribuídas as quatro unidades e seus 19 capítulos.

O capítulo analisado se chama "Vargas, tempo de ditadura", contém 13 páginas e está inserido na unidade número quatro, intitulada "O mundo em guerra". A narrativa se inicia com uma breve introdução do período, trazendo um recorte de jornal dos anos 30, com questionamentos sobre as medidas autoritárias do Governo Vargas.

Quanto à tendência historiográfica, é possível observar no capítulo analisado uma tendência ao ecletismo, trazendo principalmente as questões econômicas e políticas, sem ressaltar de maneira significativa as questões culturais

Os autores ressaltam a existência de diferentes grupos políticos envolvidos nas tensões desses 15 anos de governo, como os Integralistas e os Comunistas, enfatizando as tensões políticas entre eles e o Estado. É possível observar que, em alguns momentos, os autores trabalham o conteúdo com o intuito de mostrar a História enquanto versão, propondo aos alunos pensarem alguns conflitos pelas perspectivas de cada grupo político, como é possível observar na figura abaixo.

Figura 3 - Atividade em grupo

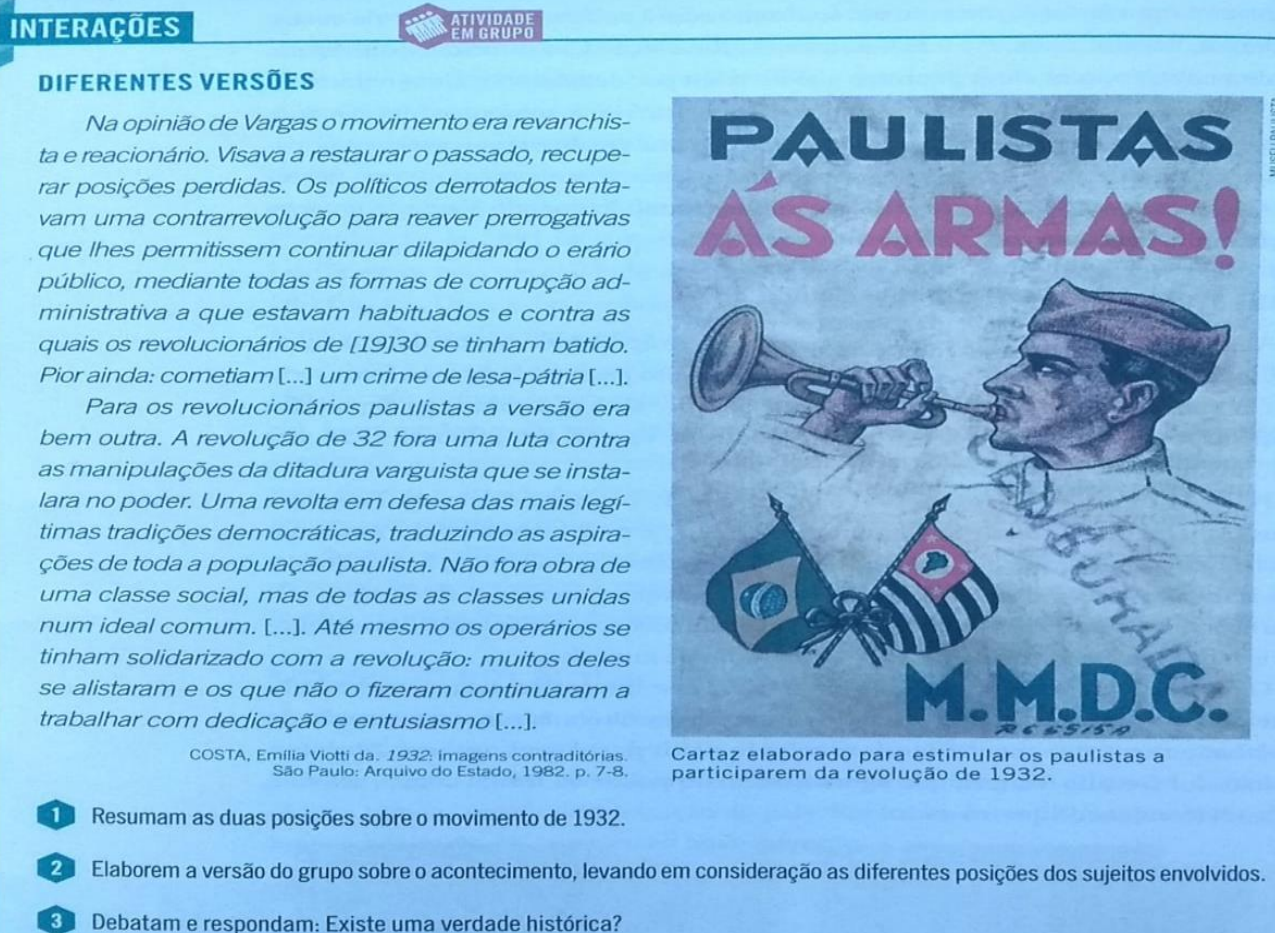

Fonte: Santiago, Pontes e Cerqueira (2015, p. 148). 
No boxe, o autor traz uma citação da historiadora Emilia Viotti Costa, de 1982, na qual ela discute a visões sobre a chamada Revolução Constitucionalista de 1932, propondo a análise da versão do Estado e dos revolucionários, questionando se existe uma verdade histórica.

Nas explicações, ao tratarem da relação dos trabalhadores com o Estado, os autores buscam mostrar que o governo ao mesmo tempo reprimiu e favoreceu os trabalhadores. Buscam enfatizar que a legislação trabalhista e as diversas medidas criadas na época foram maneiras que o Estado estruturou para controlar o movimento operário devido à forte mobilização social dos anos anteriores, passando a regular a relação entre patrão e empregado e mostrando a CLT como um desses seus instrumentos de controle. Porém, ao enfatizarem o processo de perseguição e controle exercido pelo Governo Vargas, eles colocam as organizações como desarticuladas e passam a ideia de que os trabalhadores se mantiveram calados e submissos às ações, não discutindo os processos de resistência nos quais eles estavam inseridos cotidianamente.

Os três autores apresentam uma linguagem acessível para os alunos, abordando os conteúdos de forma simples, mas como não utilizam glossário para algumas palavras e conceitos usados, dificultam sua compreensão e apreensão pelos alunos. São utilizadas diversas imagens no decorrer do capítulo que, geralmente, estão vinculadas às discussões, porém praticamente todas são apresentadas em preto e branco, não contribuído para despertar o interesse dos alunos.

De maneira geral, as atividades propostas nesse capítulo estão vinculadas às explicações e possibilitam que o aluno questione os conteúdos propostos. Grande parte dessas atividades se refere às questões trabalhistas e à relação do Estado com o operariado. Segue problematizando a legislação e a posição do Governo como formas de controlar e censurar as organizações operárias, mas sem questionar as formas de resistência e a articulação dos trabalhadores diante do processo de repressão e controle.

\section{PROJETO ARARIBÁ}

Esse livro tem como editora responsável a historiadora Maria Raquel Apolinário. A obra em questão foi construída de forma coletiva, em parceria com a Editora Moderna e seus outros colaboradores, como a assistente editorial Rosa Chadu Balbem, o coordenador de pesquisa iconográfica Luciano Bazena Gabarron e a coordenadora de revisão Adriana Bairrada. O livro contém 280 páginas, tendo nove unidades subdivididas em quatro ou cinco temas, em que a autora segue relacionando cronologicamente a História do Brasil com a História Geral. Nas primeiras páginas do livro didático, a autora propõe um manual explicativo para a melhor utilização do material didático, propondo um manual de como os alunos devem analisar as imagens e os textos argumentativos.

A unidade analisada é denominada pela autora como "A era Vargas" e está distribuída em 23 páginas. A narrativa é iniciada com uma discussão sobre a relação dos operários e o Estado durante a Segunda República, problematizando o surgimento da Legislação Trabalhista nesse período e a importância da CLT atualmente, usando o quadro Operários de Tarsila de Amaral.

As explicações estão subdivididas em três temáticas principais. A primeira trata principalmente das questões políticas, trazendo as tensões e os conflitos que emergiram nesse período; a segunda discorre sobre a economia; já a terceira trata das questões culturais, como o cotidiano e os costumes. Ao trabalhar os conteúdos, a autora traz várias citações de análises feitas por outros historiadores, buscando mostrar outras perspectivas sobre os subtemas, mas não apresenta uma discussão efetiva sobre pensar a História como versão, deixando a 
cargo do professor levantar essa problematização. No que se refere à linha historiográfica, nota-se certa tendência ao ecletismo, discutindo principalmente as questões políticas, econômicas e culturais. Contudo, parece hierarquizar, pois as questões culturais aparecem no final do capítulo.

Ao tratar das relações trabalhistas durante a Segunda República, a autora enfatiza que as novas leis criadas pelo Estado foram formas de manter os sindicatos sob seu controle, desarticulando as organizações trabalhistas independentes. Articula a política trabalhista de duas maneiras: de um lado, o governo agia para disciplinar os trabalhadores; por outro, buscava atender suas antigas reivindicações.

Discutindo brevemente o processo de luta desses trabalhadores por esses direitos, acaba por mostrar essas medidas como concessões do Estado e dos setores dominantes e não como conquistas. Por fim, é discutida a construção de uma identidade que aproximou o presidente Vargas dos trabalhadores por meio dos discursos e das grandes comemorações, o que gerou um sentimento de fraternidade do povo com relação ao presidente, como é possível observar nas cartas enviadas a ele (Figura 4).

Figura 4 - Cartas para o presidente

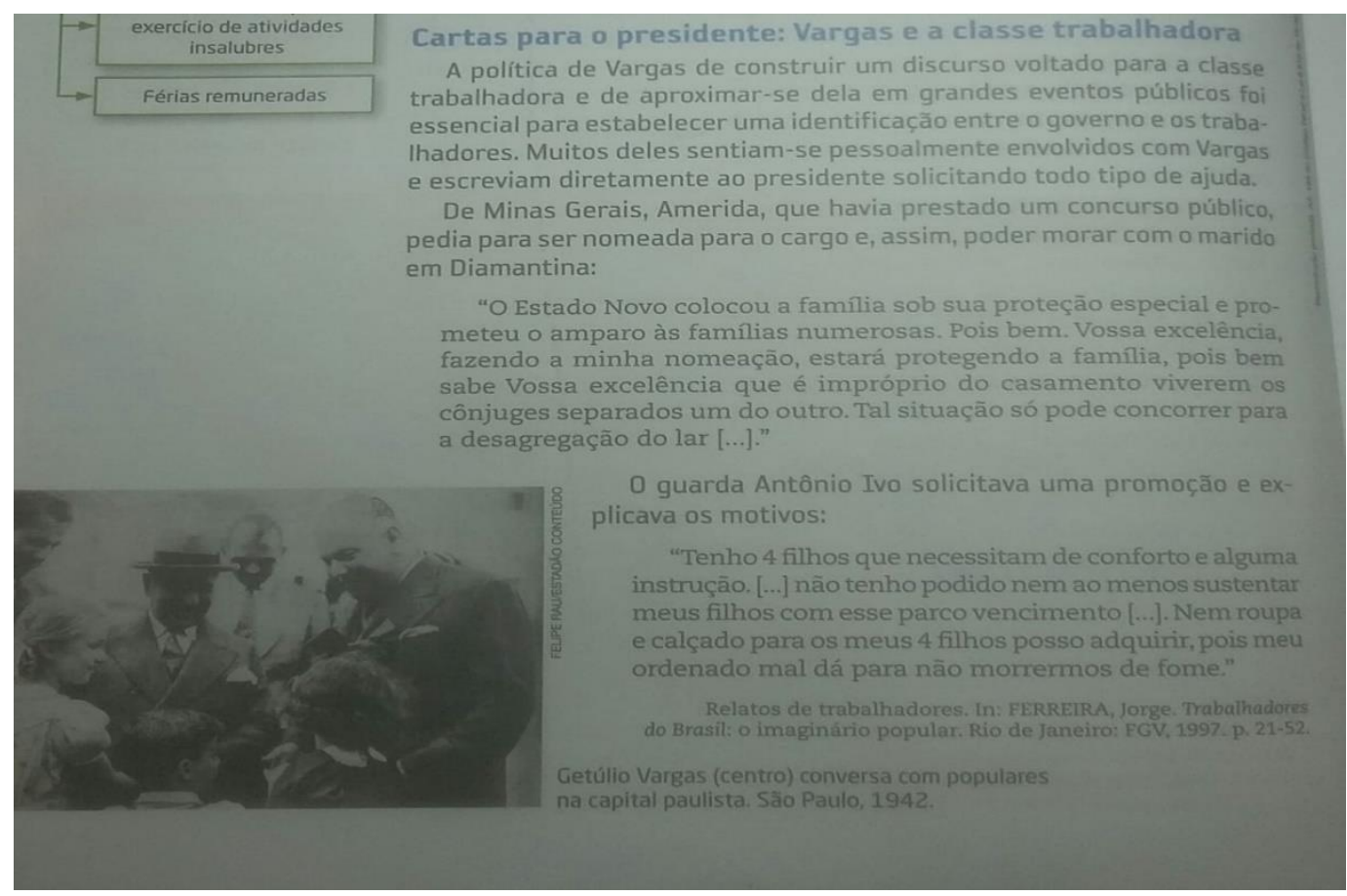

Fonte: Apolinário (2014, p. 140).

A autora discute o processo de repressão, violência e censura por meio da criação de campos de concentração, da Lei de Segurança Nacional e da criação do DIP (Departamento de Imprensa e Propaganda), buscando ressaltar o autoritarismo do Governo Vargas nesses 15 anos, principalmente durante o Estado Novo. Porém, ao denunciar essas questões, ela não discute o processo de resistência dos operários e das organizações trabalhistas, deixando margem para uma visão que mostra os trabalhadores aceitando essas medidas de bom grado ou como subjugados perante o governo e desarticulados perante as medidas, não trabalhando com a experiência dos operários durante a Segunda República.

A linguagem apresentada nas explicações é quase sempre simples e acessível, mas, sem perder a coerência, a autora também utiliza um glossário para certas palavras que julgou ser necessária uma maior explicação. No decorrer do capítulo, são utilizadas muitas imagens, que quase sempre estão vinculadas às discussões, mas não são devidamente 
problematizadas, bem como são feitas indicações de sites e filmes, possibilitando ao aluno aprofundar seus conhecimentos por meio de outras fontes.

As atividades propostas logo após as explicações estão efetivamente ligadas ao conteúdo trabalhado no capítulo. Elas possibilitam ao aluno identificar, argumentar, porém, a maioria delas estão localizadas no final do capítulo, são superficiais e acabam induzindo à memorização da resposta e não o senso crítico dos alunos. São poucas as atividades que tratam do movimento operário e da relação dos trabalhadores com o Estado, as quais acabam por ressaltar a imagem construída nas explicações, tratando as Leis Trabalhistas como concessões e medidas para cooptar as organizações sociais, não propondo uma análise das ações dos trabalhadores ante essas medidas.

\section{HISTÓRIA DOC}

Esse livro foi escrito pelos historiadores Ronaldo Vainfas, Sheila de Castro Faria, Jorge Ferreira e Daniela Buono Calainho e publicado pela editora Saraiva. Tendo como editora responsável Kelen L. Giordano Amaro; como coordenadora de iconografia Cristina Akisino; e como coordenadora de revisão Camila Christi Gazzani. O livro contém 448 páginas, com cinco unidades subdivididas em 18 capítulos, cujos conteúdos são apresentados de forma alternada entre a História Geral e a História do Brasil.

O capítulo denominado "Governo Vargas e reformas sociais no Brasil" contém 16 páginas e está dentro da unidade intitulada "Crises e guerras". A narrativa é iniciada com um breve resumo do processo que levou o grupo político de Getúlio Vargas ao poder. No início, também é apresentada uma imagem que mostra o Presidente visitando uma aldeia indígena, no Parque Nacional do Araguaia, e uma problematização sobre quem foi Getúlio Vargas na História do Brasil.

Os conteúdos são dispostos de forma cronológica, por meio de uma linha do tempo, na qual os autores ressaltaram datas e acontecimentos que consideram mais relevantes, como é comum na historiografia tradicional. No que compreende a tendência histórica predominante no livro, foi possível observar uma tendência ao ecletismo, com foco principalmente para as questões políticas e culturais.

De forma geral, as explicações são bem elaboradas, buscando trazer os fatos históricos dentro do processo, trazendo o contexto nacional paralelamente ao contexto global. Os autores ressaltam o envolvimento dos vários grupos políticos durante a Segunda República, como os Liberais, Comunistas e os Integralistas. Destacam as tensões e os conflitos nos quais estes estavam inseridos. Os autores utilizam o conceito de Revolução de 1930, não trabalham com o conceito de Golpe para analisar o movimento que resultou na ascensão de Getúlio Vargas à Presidência da República. Também não é utilizada a expressão "Intentona Comunista" e sim "Revolta Comunista" para denominar as rebeliões que o Partido Comunista promoveu em 1935. Os autores buscam problematizar em alguns momentos o uso de diferentes fontes, como podemos observar na imagem apresentada abaixo. 
Figura 5 - A história não está sozinha

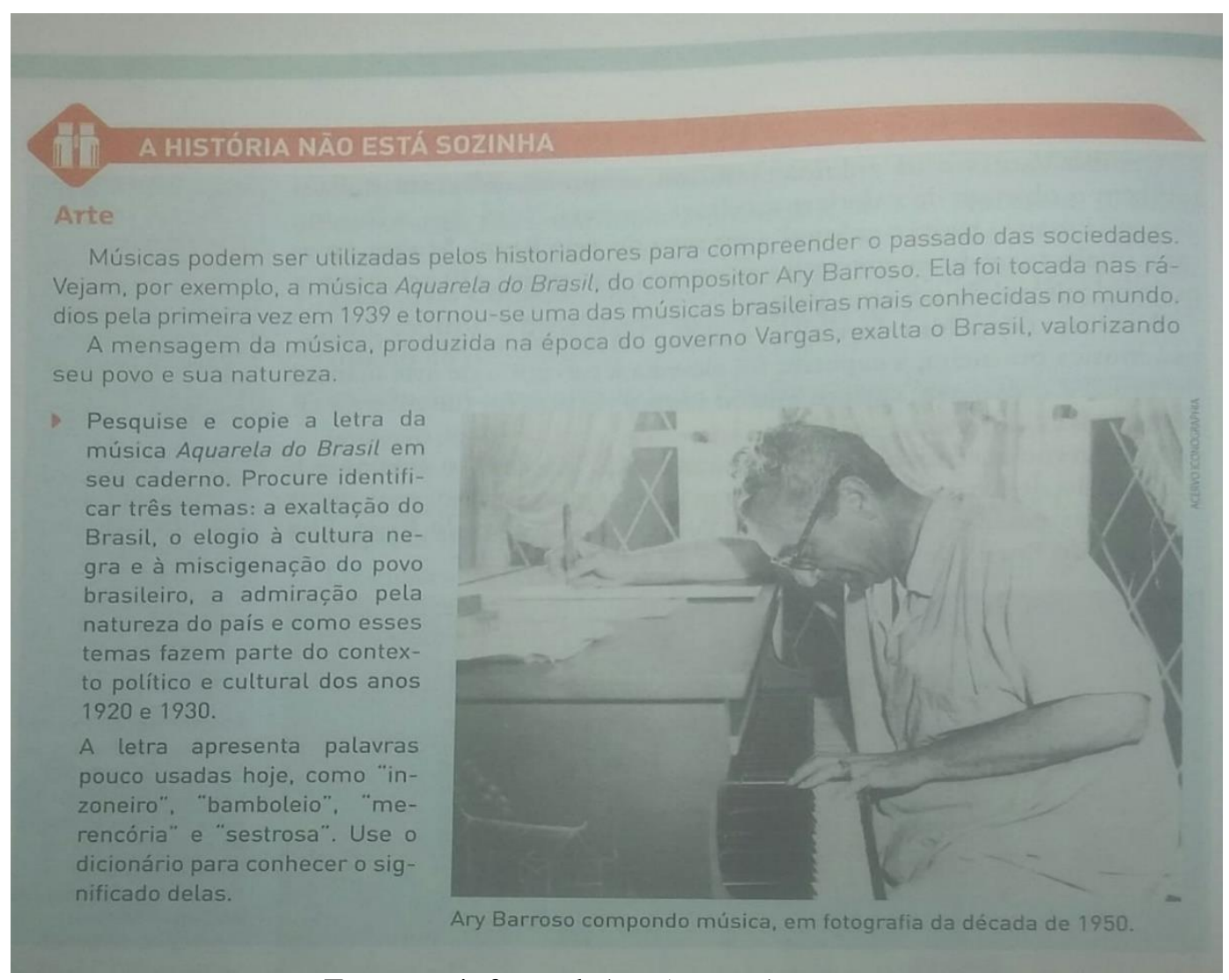

Fonte: Vainfas et al. (2015, p. 134).

Nesse boxe, é proposto que os alunos trabalhem com a música "Aquarela do Brasil", de Ary Barroso, como fonte de pesquisa para pensarem o nacionalismo posto em prática no Governo Vargas, oportunizando a discussão sobre a História como versão e não como verdade única.

Ao discorrer sobre a relação dos trabalhadores com o Estado, os autores trabalham o período do Estado Novo como sendo o único momento em que o Estado foi autoritário. Discutem apenas brevemente o processo de luta no qual o movimento operário estava inserido durante a Primeira República e, dessa maneira, apontam a legislação como recebida de bom grado pelos trabalhadores, problematizando superficialmente o processo de cooptação e controle dos sindicatos, mostrando os trabalhadores como subjugados e desarticulados. Não discutem a insatisfação nem o processo de resistência por parte da classe trabalhadora.

Também utilizam muitas imagens e cartazes, problematizando-os junto com as discussões trabalhadas, oportunizando aos alunos variadas fontes. A linguagem utilizada nas explicações é acessível aos alunos, e os autores fazem uso de um glossário para trazer o significado de palavras e conceitos, oportunizando uma melhor compreensão e apreensão do que está ali proposto.

No que tange às atividades propostas no decorrer do capítulo, nota-se mais afinidade com as discussões trabalhadas nas explicações, trazendo maior aprofundamento do conteúdo e permitindo ao aluno refletir sobre as discussões. Em relação às atividades que estão no final capítulo, elas se mostram mais superficiais, menos aprofundadas nos textos e acabam apenas induzindo à resposta "correta" e à memorização. Os autores não propõem atividades que tratam das organizações operárias e da reestruturação da legislação trabalhista, apenas questionam a relação dos direitos trabalhistas com a construção da cidadania. 


\section{CONSIDERAÇÕES FINAIS}

A partir da análise, pode-se concluir que nos cinco livros didáticos analisados, de maneira geral, aparece uma tendência ao ecletismo, visto que abordam aspectos que permeiam a História política, partindo da "tradicional à renovada História política, à História socioeconômica e a uma História cultural. Os livros foram escritos, a maioria, por historiadores e pedagogos.

Nos livros analisados, foram encontradas diferentes versões, sendo elas: a que apresenta a legislação trabalhista como uma conquista dos trabalhadores, os quais se articularam de diversas formas, como nas associações mutualísticas e nos sindicatos independentes durante a Primeira República, que oportunizaram diversas ações para a melhoria da vida dos trabalhadores, resistindo e pressionando o Estado e os setores dominantes. Que retrata como o governo de Vargas buscou construir uma imagem de si como um grande líder por meio das medidas voltadas para as questões sociais, tendo como objetivo manter o domínio sobre os trabalhadores, construindo a política paternalista por meio da censura e da propaganda na construção da imagem de "pai dos pobres".

Outra visão que foi possível observar é a que trata brevemente das ações autoritárias e controladoras do Governo Vargas, sem discutir efetivamente sobre os anos de movimento e organização dos trabalhadores, que vinham ocorrendo antes mesmo do período. Acaba por apresentar as ações do Estado como grandes feitos, considerando a legislação trabalhista e outras medidas como uma concessão feita pelo Estado e pelos setores dominantes aos trabalhadores.

Tanto na produção bibliográfica produzida pela historiografia quanto nos livros didáticos, pode-se observar que as discussões propostas apenas tratam das relações do Estado com o operariado, como consequência das leis e das medidas que entraram em vigor nesse período, não procurando pensar/mostrar a classe operária como se constituindo ante seu cotidiano, sua cultura e experiência. Dessa forma, mesmo que os autores discutam sobre os trabalhadores e sua luta nas explicações, os operários ainda são colocados apenas como coadjuvantes ou submissos ao serem apresentados. Dessa forma, por mais que se possa perceber uma tentativa de afastamento da História, que traz os grandes feitos de Vargas como um herói, esse discurso ainda permanece intrinsecamente dentro do texto.

Para compreender a experiência dos trabalhadores durante a Segunda República, devemos entender que de maneira geral esses trabalhadores não deixaram de resistir e exigir melhores condições de vida e trabalho, mesmo dentro de um contexto autoritário. Eles, apesar dessa estrutura, continuaram produzindo ações e não se calaram, passaram apenas a exercê-las de outras maneiras, como podemos observar no processo de criminalização das greves e na paralização dos trabalhadores que continuou a acontecer. No entanto, eles não a denominaram mais assim. Da mesma forma, podemos nos voltar para os processos na Justiça do Trabalho e vermos como os trabalhadores, de maneira individual ou coletiva, buscavam reivindicar condições mais dignas.

Portanto, consideramos necessário repensar a relação entre o Estado e o operariado por uma nova perspectiva que não coloque os trabalhadores no papel de silenciados, mas que apresente sua experiência durante esse período e, dessa maneira, permita dar voz aos trabalhadores.

\section{REFERÊNCIAS}


APOLINÁRIO, Maria Raquel. Projeto Araribá: 9ª ano. 4. ed. São Paulo: Moderna, 2014.

BARISTELA, Alessandro. A Era Vargas e o movimento operário e sindical brasileiro (19301945). UNOESC \& Ciência - ACHS, Joaçaba, v. 6, n. 1, p. 21-34, jan./jun. 2015.

BATALHA, Claudio Henrique de Moraes. A Formação da Classe Operária e Projetos de Identidade Coletiva. In: FERREIRA, Jorge; DELGADO, Lucilia de Almeida Neves. O Brasil Republicano. Vol. 1. Rio de Janeiro: Civilização Brasileira, 2003.

BENTO, Luiz Carlos. Livro didático e historiografia: um debate acerca do conceito de História produzido pelos livros didáticos, entre 2001 e 2005. Disponível em: <http://www.nee.ueg.br/seer/index.php/interfaces/article/viewFile/58/85. s/d.>. Acesso em: 16 jul. 2018.

BITTENCOURT, Circe Maria Fernandes. Ensino de História: fundamentos e métodos. São Paulo: Cortez, 2004.

BOITO JÚNIOR, Armando. O Sindicalismo de Estado no Brasil: uma análise crítica da estrutura sindical. São Paulo: HUCITEC, 1991.

BOULOS JÚNIOR, Alfredo. História, sociedade e cidadania: $9^{\circ}$ ano do Ensino Fundamental II. Manual do Professor. São Paulo: FTD, 2015.

BRASIL. Ministério da Educação. PNLD. 2018. Disponível em: < http://portal.mec.gov.br/busca-geral/318-programas-e-acoes-1921564125/pnld439702797/12391-

pnld\#: :text $=\mathrm{O} \% 20$ Programa $\% 20 \mathrm{Nacional} \% 20 \mathrm{do} \% 20$ Livro,redes $\% 20$ federal $\% 2 \mathrm{C} \% 20$ est aduais $\% 2 \mathrm{C} \% 20$ municipais $\% 20 \mathrm{e}>$. Acesso em: 16 ago. 2018.

CAPELATO, Maria Helena. O Estado Novo: o que trouxe de novo? In: FERREIRA, Jorge; DELGADO, Lucilia de Almeida Neves (org.). O Brasil republicano: o tempo do nacionalestatismo (1930-1945). Rio de Janeiro: Civilização Brasileira, 2003.

D’ARAÚJO, Maria Celina. Estado, classe trabalhadora e políticas sociais. In: FERREIRA, Jorge; DELGADO, Lucilia de Almeida Neves (org.). O Brasil republicano: o tempo do nacional-estatismo (1930-1945). Rio de Janeiro: Civilização Brasileira, 2003.

FERREIRA, Jorge; DELGADO, Lucilia de Almeida Neves (org.). O Brasil Republicano: o tempo do nacional-estatismo do início da década de 1930 ao apogeu do Estado Novo. Rio de Janeiro: Civilização Brasileira, 2003.

GOMES, Ângela de Castro. Burguesia e trabalho: política e legislação social no Brasil (1917-1937). Rio de Janeiro: Campus, 2015.

GOMES, Ângela de Castro. A invenção do trabalhismo. 3. ed. Rio de Janeiro: FGV, 2005.

PANDOLFI, Dulce Chaves. Os anos de 1930: as incertezas de um regime. In: FERREIRA, Jorge; DELGADO, Lucilia de Almeida Neves (org.). O Brasil republicano: o tempo do nacional-estatismo (1930-1945). Rio de Janeiro: Civilização Brasileira, 2003. 
PONTES, Maria Aparecida; CERQUEIRA, Célia; SANTIAGO, Pedro. Integralis história: $9^{\circ}$ ano. 1. ed. São Paulo: IBEP, 2015.

REIS, José Carlos. A história, entre a filosofia e a ciência. 4. ed. Belo Horizonte: Autêntica Editora, 2011.

SANTIAGO, Pedro; PONTES, Maria Aparecida; CERQUEIRA, Célia. Coleção Integralis: $9^{\circ}$ ano do Ensino Fundamental. Manual do Professor. 1. ed. São Paulo: Editora IBEP, 2015.

SIQUEIRA, Gustavo Silveira. Experiências de greve no Estado Novo. Direito e Práxis, Rio de Janeiro, v. 06, n. 11, p. 226-253, mar. 2015.

THOMPSON, Edward Palmer. A Formação da Classe Operária Inglesa. Volumes I, II e III. Rio de Janeiro: Paz e Terra, 1987.

THOMPSON, Edward Palmer. A Miséria da teoria: Ou um planetário de erros. Rio de Janeiro: Zahar, 1981.

VAINFAS, Ronaldo; FARIAS, Sheila de Castro; FERREIRA, Jorge; CALAINHO, Daniela Buono. História Doc: $9^{\circ}$ ano. 1. ed. São Paulo: Saraiva, 2015.

VICENTINO, Cláudio; VICENTINO, José Bruno. Projeto Mosaico: História: anos finais: ensino fundamental. 1. ed. São Paulo: Scipione, 2015.

Submetido: 05/04/2019

Aprovado: 18/02/2020 